\title{
Analytical method development and validation of hydrocortisone and clotrimazole in topical dosage form using RP-HPLC
}

\author{
Dure Najaf lqbal, Adeel Ashraf, Munawar lqbal and Arif Nazir
}

\begin{abstract}
Background: Different pharmaceutical topical agents are available in the market for the treatment of fungal infections. A simple, precise, and cost-effective RP-HPLC method was developed and validated for the determination of hydrocortisone and clotrimazole simultaneously in a topical cream dosage form. Chromatographic separation was done on USP L1 $(250 \times 4.6) \mathrm{mm}$ column with a particle size of $5 \mu \mathrm{m}$. The mobile phase employed for this study consists of acetonitrile and buffer in the ratio of 75:25, respectively. The flow rate was kept at $1 \mathrm{~mL}$ per minute. The detection of the drug was carried out at $254 \mathrm{~nm}$ using a UV detector. The retention times of HYD and $\mathrm{CL}$ were 3.0 min and 7.3 min, respectively.

Result: The method is developed and validated for linearity, precision, specificity, accuracy, and robustness. Conclusion: The stability of finished products gives us knowledge about the effect of different environmental factors like humidity, light, and temperature, and these factors give us information about the quality of finished products.
\end{abstract}

Keywords: RP-HPLC, Validation, Stability study, Stress testing, Accuracy, Precision

\section{Background}

Dermatophyte has a Greek origin and is known as the skin of the plant [1]. Dermatophytes are divided into three fungal groups that cause dermal diseases in humans and animals [2]. The asexual dermatophytes are divided into three types, i.e., Trichophyton, Microsporum, and Epidermophyton [3, 4]. These cause different types of infections like Tinea pedis (athlete's foot), Tinea cruris (jock itch), Tinea corpora (ringworm of the body), and Tinea faciei (facial ringworm). Different pharmaceutical topical agents are available in the market for the treatment of these fungal infections either alone or in a combination. The combination which is used most widely is a combination of hydrocortisone (HYD) and

\footnotetext{
* Correspondence: anmalik77@gmail.com

Department of Chemistry, The University of Lahore, Lahore, Pakistan
}

clotrimazole (CL). Cortisol is a hormone which is supplied with the name of hydrocortisone when is used as medication [5]. It is used for the treatment of dermatitis, adrenogenital syndrome, asthma, adrenocortical insufficiency, rheumatoid arthritis, and chronic obstructive pulmonary disease (COPD) [6]. It can be used in the form of pills, creams, and injections. It can also be used as immune suppression and as an anti-inflammatory. The chemical formula of hydrocortisone is $11 \beta, 17 \alpha$, 21-trihydroxypregn-4-ene-3,20-dione, and the molecular formula is $\mathrm{C}_{21} \mathrm{H}_{30} \mathrm{O}_{5}$. It is a naturally occurring steroid [7].

Clotrimazole $(\mathrm{CL})$ is used as an antifungal drug. It is used for the treatment of vaginal yeast infections, pityriasis versicolor, diaper rash, oral thrush, and types of ringworm as well as jock itch and athlete's foot [8]. It can be given as topically or orally. CL is also used for

\section{Springer Open}

(C) The Author(s). 2020 Open Access This article is licensed under a Creative Commons Attribution 4.0 International License, which permits use, sharing, adaptation, distribution and reproduction in any medium or format, as long as you give appropriate credit to the original author(s) and the source, provide a link to the Creative Commons licence, and indicate if changes were made. The images or other third party material in this article are included in the article's Creative Commons licence, unless indicated otherwise in a credit line to the material. If material is not included in the article's Creative Commons licence and your intended use is not permitted by statutory regulation or exceeds the permitted use, you will need to obtain permission directly from the copyright holder. To view a copy of this licence, visit http://creativecommons.org/licenses/by/4.0/. 
the treatment of yeast infection (vulvovaginal candidiasis) or infection of the skin caused by yeast. For skin infections, CL is used for 2-8 days twice daily [9]. Clotrimazole inhibits the growth of Candida by modifying the penetrability of the fungal cell wall. It binds with phospholipids in the cell membrane and hinders the synthesis of ergosterol and other types of sterols which are necessary for cell membrane production $[10,11]$. The chemical formula of CL is 1-[(2-chlorophenyl) diphenyl methyl]-1H-imidazole, and molecular formula is $\mathrm{C}_{22} \mathrm{H}_{17} \mathrm{ClN}_{2}$. The structural formula of both hydrocortisone and clotrimazole is given in Fig. 1.

Literature survey disclose that different methods are available for detection of HYD and CL separately; for HYD, these are polarographic [12, 13], HPLC [14, 15], spectrophotometric [16], TLC [17], and LC-MS/MS [18, 19] methods; and for CL, these are spectrophotometric [20], HPLC methods [21, 22], and titrimetric [23] TLC [24] methods. Only one method has been reported for the simultaneous determination of HYD and CL that is HPTLC [25]. The aim of this work was to develop and validate a new, novel, and different method for the simultaneous determination of HYD and CL in a topical cream and in a raw form. The proposed method is simple, accurate, selective, rapid, and less time-consuming as compared with the existing HPTLC method. The given method has been developed and validated according to ICH guidelines [26].

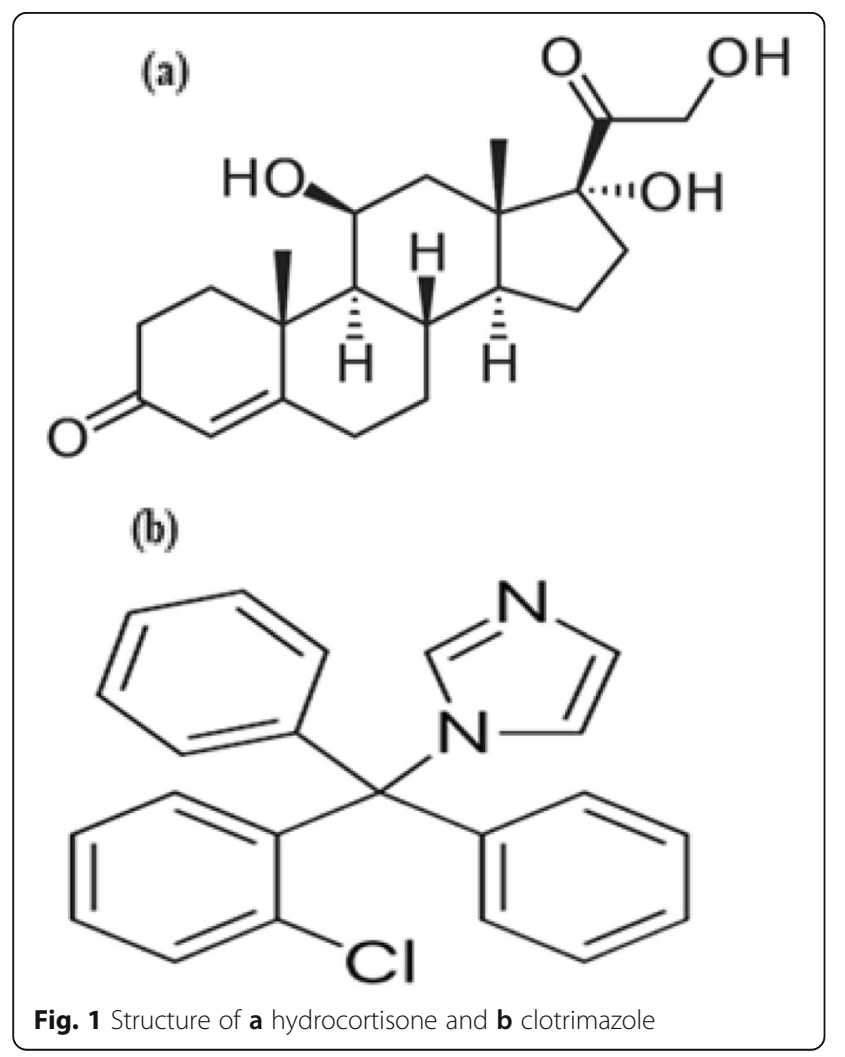

The stability of finished products gives us knowledge about the effect of different environmental factors like humidity, light, and temperature, and these factors give us information's about the quality of finished products. The shelf life of finished products can also be decided on the basis of stability study [27-29]. Stability assay precisely measures the pharmaceutical active ingredients, without interfering, from the process impurities, degradation products, potential impurities, or other excipients [30].

\section{Methods}

Reagents and chemicals

HYD was received from the Tianjin Tianmao Technology Development (China). CL was received from the Srikem Laboratories Pvt. Limited (India). The purity of HYD \& CL was found to be $100 \%$ and $99.3 \%$ on a dried basis. HPLC grade acetonitrile, HPLC grade water, and dibasic potassium phosphate were received from the Merck. All other reagents which are used are of analytical grade. All chemicals and reagents which are used for RP-HPLC were filtered through $0.45-\mu \mathrm{m}$ filter paper.

\section{Chromatographic conditions}

Chromatographic separation was attained at $40{ }^{\circ} \mathrm{C}$ with a mobile phase consisting of acetonitrile and buffer solution (dissolve $4.35 \mathrm{~g}$ of dibasic potassium phosphate in water to make $1000 \mathrm{~mL}$ of solution) in the ratio of 75 : 25 , respectively, and is degassed by using an ultrasonic bath. Isocratic elution was achieved on the USP L1 (250 $\times 4.6) \mathrm{mm}$ column with a particle size of $5 \mu \mathrm{m}$. The flow rate was kept at $1.0 \mathrm{~mL} / \mathrm{min}$, and the injection volume was $20 \mu \mathrm{L}$. UV detection was achieved at $254 \mathrm{~nm}$.

\section{Preparation of standard stock solution}

Standard solution of $0.2 \mathrm{mg} / \mathrm{mL}$ concentration of both HYD and CL was prepared by equally weighing the quantity of both the standards and transferring them into 100 volumetric flasks. Then add $70 \mathrm{~mL}$ of mobile phase and mix to dissolve, make up the volume to the mark with the mobile phase, and mix and sonicate the solution to degas.

\section{Preparation of sample solution}

Mix three tubes of Aquazole creams, then accurately weigh the quantity of $2 \mathrm{~g}$ of the cream containing $20 \mathrm{mg}$ of APIs of both HYD and CL in a 100-mL volumetric flask and add $70 \mathrm{~mL}$ of a mobile phase and sonicate it. Sonication was done to dissolve the APIs completely then make up the volume to the mark with the same diluent and mix. The final solution is filtered using a filter paper of $0.45-\mu \mathrm{m}$ pore size. Then, $20 \mu \mathrm{L}$ of the sample was injected into HPLC. 


\section{Stability study-stress study}

A stress study was performed in an experimental cream sample and working standards in order to check the degradation of products. The stability-indicating nature and selectivity of the given analytical method were also checked.

The starting point of testing was to check the degradation of both HYD and CL individually under different stress conditions [31]. Temperature stress was applied to the experimental cream formulation of HYD and CL and its placebo. This test was carried out in the oven at $50{ }^{\circ} \mathrm{C}$ and in climatic chamber at $40{ }^{\circ} \mathrm{C} \pm 2$ and $75 \% \pm 5$ RH (relative humidity). These samples were placed for 3 months under $50{ }^{\circ} \mathrm{C}$ conditions and for 6 months under $40{ }^{\circ} \mathrm{C} \pm 2$ and $75 \% \pm 5 \mathrm{RH}$ conditions.

For photolytic stress, working standard solutions, experimental cream formulation, and its placebo were exposed directly to sunlight at outside temperature 28$32{ }^{\circ} \mathrm{C}$ for $10 \mathrm{~h}$ during the disclosure time. All samples were located outside in firmly closed quartz cells. Simultaneously, all experimental samples were placed at room temperature protected from light.

\section{Results}

\section{Method development}

A mobile phase consisting of acetonitrile and buffer in the ratio of $(75: 25)$ was used with $20-\mu \mathrm{L}$ injection volume of $0.2-\mathrm{mg} / \mathrm{mL}$ concentration separately for hydrocortisone and clotrimazole. A symmetrical peak was acquired on $3.046 \mathrm{~min}$ for hydrocortisone and similarly a symmetrical peak at $7.368 \mathrm{~min}$ was acquired for clotrimazole. Similarly, it was observed that different parameters like column type and $\mathrm{pH}$ also have different effects on HYD and CL. System suitability parameters were tested according to USP. A chromatogram of simultaneous detection of HYD and CL is given in Fig. 2.

\section{System suitability}

For the purity of working standards, we injected six standard injections, and their RSD, tailing factor, theoretical plates, and resolution were calculated and given in Table 1 . System suitability parameters confirmed that the given chromatographic conditions were good for the method development and validation.

\section{Method validation \\ Selectivity and linearity}

Linearity solutions were prepared by quantitative dilutions of the stock solution of hydrocortisone and clotrimazole standard to attain solutions in the series of 50 to $150 \%$ (i.e., $50 \%, 75 \%, 100 \%, 125 \%$, and $150 \%$ ) of the working concentration. All the prepared solutions were triply analyzed, and their response was recorded by injecting. The correlation coefficient $(r)$ should not be less than 0.999, is considered as acceptable, and was obtained for both HYD and CL. The correlation coefficient and regression plot were presented in Table 2 .

\section{Accuracy and precision}

Accuracy was tested by spiking known quantities of HYD and CL in the placebo of cream. The accuracy samples were prepared at three-level concentrations over a range of $75 \%, 100 \%$, and $125 \%$. The obtained recovery result should be between 98 and 100\% and their \%age RSD should not be more than 2 (RSD $\leq 2 \%$ ). The accuracy results were found to be well within the limits which are given in Table 2.

\section{Range and robustness}

The concentration interval for HYD and CL over which acceptable linearity, precision, and accuracy were obtained is given in Table 2. Robustness was performed regarding wavelength, oven temperature, and flow rate.

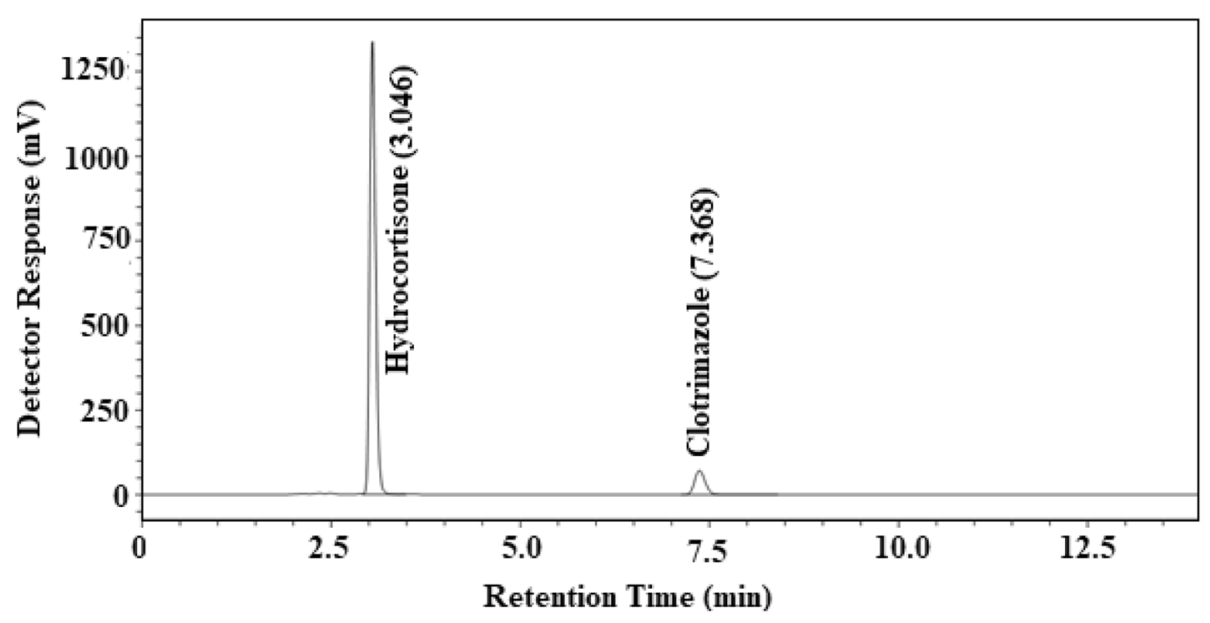

Fig. 2 HPLC chromatogram of working standards 
Table 1 Parameters of system suitability for hydrocortisone and clotrimazole

\begin{tabular}{lllll}
\hline Drugs & Retention time $(\mathrm{min})$ & Instrument precision $(\mathrm{RSD} \leq 2 \%)$ & Theoretical plates $(\geq 2000)$ & Tailing factor $(0.8-2.0)$ \\
\hline Hydrocortisone & 3.027 & 0.16 & 23462 & 1.177 \\
& 3.025 & 0.29 & 23457 & 1.188 \\
& 3.035 & 0.17 & 23548 & 1.188 \\
& 3.046 & 0.36 & 23478 & 1.185 \\
& 3.021 & 0.35 & 23386 & 1.185 \\
& 3.015 & 0.22 & 23478 & 1.183 \\
& 7.314 & 0.22 & 5298 & 1.892 \\
& 7.303 & 0.42 & 5326 & 1.885 \\
& 7.302 & 0.27 & 5308 & 1.896 \\
& 7.368 & 0.23 & 5297 & 1.880 \\
\end{tabular}

The results which were obtained are within acceptable limits that are $98-100 \%$ and their RSD is $0.23 \%$ for HYD and $0.36 \%$ for CL.

\section{$\angle O D$ and $L O Q$}

The LOD of an analytical method is the lowest quantity of analyte in a given sample which can be easily detected but not quantified to the given value. The LOQ of an analytical method is the lowest amount of analyte in a given sample which can be easily quantified with appropriate accuracy and precision. LOD and LOQ for both HYD and CL were calculated and are given in Table 2.

\section{Stress testing}

Initially, the physical appearance of experimental cream was off-white and homogeneous and chromatograms of initial testing were given in Fig. 3. Degradation of HYD and $\mathrm{CL}$ was also observed and tested after 3 and 6 months at $40{ }^{\circ} \mathrm{C} \pm 2 / 75 \% \pm 5 \mathrm{RH}$, no change in physical appearance observed, and little degradation of HYD and CL was observed (Fig. 4). The results for the assay of both HYD and CL are given in Table 3. The results of a sunlight stress are given in Table 3 . The developed and validated stability indicating method was also applied for the detection of HYD and CL assay in two topical creams from the market: Clozox $\mathrm{H}$ and Gytrim $\mathrm{HC}$ labeled on HYD and CL content.

\section{Discussion}

After studying molecular structure and solubility, the method development was started according to hydrophobic interaction and polarity of hydrocortisone and clotrimazole. The process development was carried out at $1.0 \mathrm{~mL}$ per min flow rate, and the chromatographic temperature (column temperature) was $40{ }^{\circ} \mathrm{C}$. In the start, a mobile phase consisting of acetonitrile and buffer was used with a $20-\mu \mathrm{L}$ injection volume of a $0.2-\mathrm{mg} / \mathrm{mL}$ concentration separately for hydrocortisone and clotrimazole. The peaks which were obtained are symmetrical, so there was no necessity for method optimization of unusual chromatograms, i.e., asymmetrical peaks, overlapping. In order to reduce the peaks' retention time and to make the method cost-effective only play with the composition of the mobile phase.

Similarly, it was observed that different parameters like column type and $\mathrm{pH}$ also have different effects on HYD and CL. System suitability parameters were tested according to USP.

The working standard solution of HYD and CL was injected separately into HPLC to determine their retention time, and also chromatographic purity and UV spectrum. Then, the working standard solution of a mixture of HYD

Table 2 Validation parameters for hydrocortisone and clotrimazole assay

\begin{tabular}{|c|c|c|c|c|c|c|c|c|}
\hline \multirow{3}{*}{$\begin{array}{l}\text { Working } \\
\text { standards }\end{array}$} & \multicolumn{8}{|l|}{ Validation parameters } \\
\hline & \multirow{2}{*}{$\begin{array}{l}\text { Linearity regression } \\
\text { plot }\end{array}$} & \multicolumn{2}{|c|}{ Repeatability } & \multirow{2}{*}{$\begin{array}{l}\text { Range } \\
(\mu \mathrm{g} / \mathrm{ml})\end{array}$} & \multicolumn{2}{|l|}{ Accuracy } & \multirow{2}{*}{$\begin{array}{l}\mathrm{LOQ} \\
(\mu \mathrm{g} / \\
\mathrm{ml})\end{array}$} & \multirow{2}{*}{$\begin{array}{l}\text { LOD } \\
(\mu \mathrm{g} / \\
\mathrm{ml})\end{array}$} \\
\hline & & $\mathrm{R}$ & $\mathrm{RSD}(\%)$ & & Mean recovery & RSD (\%) & & \\
\hline Hydrocortisone & $y=15902 x-36428$ & 0.9996 & 0.36 & $100-300$ & 101.07 & 0.03 & 43.62 & 14.39 \\
\hline Clotrimazole & $y=60335 x-3142$ & 0.9994 & 0.23 & $100-300$ & 101.13 & 0.08 & 34.03 & 11.23 \\
\hline
\end{tabular}




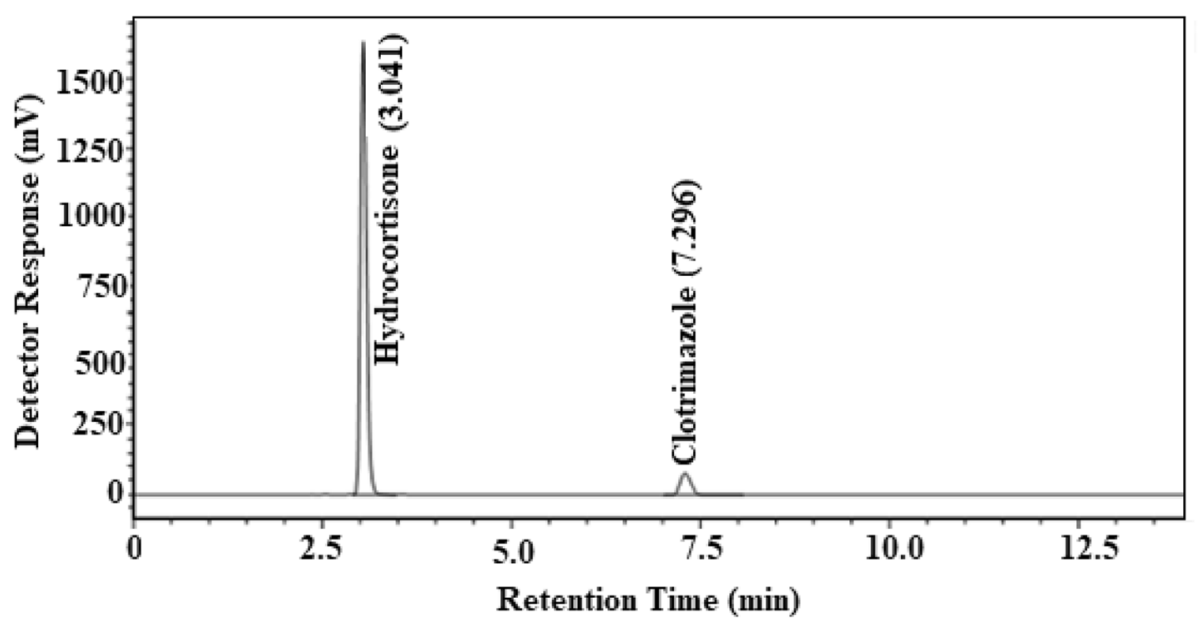

Fig. 3 HPLC chromatogram of aquazole cream

and CL was injected, and their retention time, chromatographic purity, and UV spectrum were confirmed. For this purpose, we injected six standard injections, and their RSD, tailing factor, theoretical plates, and resolution were calculated. System suitability parameters confirmed that the given chromatographic conditions were good for the method development and validation.

The mixture of working standard solutions, placebo of cream, and blank was injected separately, and chromatograms are obtained; no extra peak was observed. The peaks which are obtained are of HYD and CL in the cream formulation. Linearity solutions were prepared by quantitative dilutions of the stock solution of hydrocortisone and clotrimazole. The correlation coefficient $(r)$ should not be less than 0.999, is considered as acceptable, and was obtained for both HYD and CL.

Accuracy was tested by spiking known quantities of HYD and CL in the placebo of cream. The accuracy samples were prepared at three-level concentrations over a range of $75 \%, 100 \%$, and $125 \%$. The obtained recovery result should be between 98 and 102\%, and their \%age RSD should not be more than 2 (RSD $\leq 2 \%$ ). There are three stages of precision: intra-assay precision(repeatability), reproducibility, and intermediate precision [32]. Repeatability of the suggested analytical method was carried out by making six samples and injecting each of them three times in HPLC of the selected cream formulation. All the results which were obtained met the requirements $\mathrm{RSD} \leq 2 \%$ and are given in Table 2 . Intermediate precision was performed on the same sample on different days by two different analyses. The value of RSD is not more than $2 \%$ for both HYD and CL.

The concentration interval for HYD and CL over which acceptable linearity, precision, and accuracy were obtained is given in Table 2. Robustness was performed regarding wavelength, oven temperature, and flow rate.

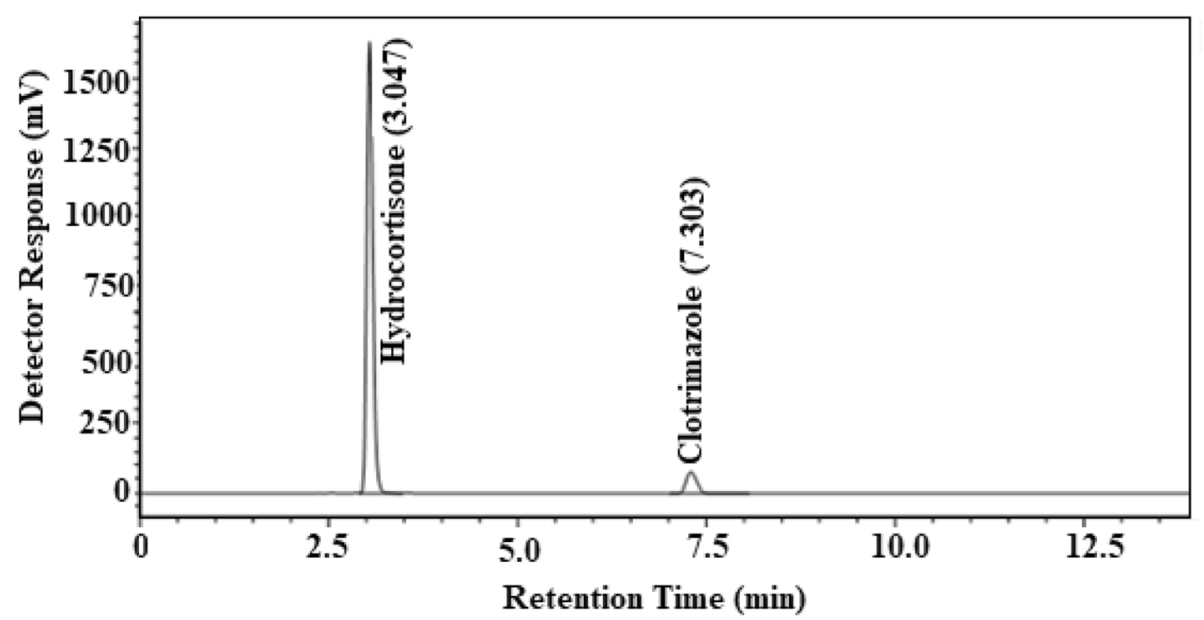

Fig. $4 \mathrm{HPLC}$ chromatogram of topical cream stress testing at $40{ }^{\circ} \mathrm{C} \pm 2 / 75 \% \pm 5 \mathrm{RH}$ (after 6 months) 
Table 3 Stress study of hydrocortisone and clotrimazole assay for experimental topical cream at $40{ }^{\circ} \mathrm{C}$ temperature and sunlight

\begin{tabular}{lllll}
\hline Working standards & Initial analysis (\%) & $40{ }^{\circ} \mathrm{C} \pm 2 / 75 \% \pm 5 \mathrm{RH}(3 \mathrm{months})$ & $40^{\circ} \mathrm{C} \pm 2 / 75 \% \pm 5 \mathrm{RH}(6 \mathrm{months})$ & Sunlight $10 \mathrm{~h}\left(28-32{ }^{\circ} \mathrm{C}\right)$ \\
\hline Hydrocortisone & 99.89 & 99.47 & 98.63 & 98.56 \\
Clotrimazole & 99.87 & 98.52 & 98.45 & 98.67
\end{tabular}

The results which were obtained are within acceptable limits that are $98-102 \%$, and their RSD is $0.18 \%$ for HYD and $0.34 \%$ for CL.

The LOD of an analytical method is the lowest quantity of analyte in a given sample which can be easily detected but not quantified to the given value. The LOQ of an analytical method is the lowest amount of analyte in a given sample which can be easily quantified with appropriate accuracy and precision.

Initially, physical appearance of experimental cream was off-white and homogeneous and chromatograms of initial testing were given in Fig. 3. The samples were tested after 3 months at $50{ }^{\circ} \mathrm{C}$ stress condition, and it was observed that the physical appearance of a sample remains almost the same and little degradation of HYD and CL was observed. The degradation of HYD and CL was also observed and tested after 3 and 6 months, no change in physical appearance observed, and little degradation of HYD and CL was observed (Fig. 4). These conditions are not as much drastic as $50{ }^{\circ} \mathrm{C}$. The placebo sample was also tested in both conditions, and it also shows no change in physical appearance and almost the same results were obtained as at initial conditions.

Sunlight stress on experimental topical cream shows that little degradation of HYD and CL was observed, and a physical appearance of cream also remains nearly unchanged. The developed and validated stability indicating method was also applied for the detection of HYD and $\mathrm{CL}$ assay in three topical creams from the market: Clozox $\mathrm{H}$ and Gytrim labeled on HYD and CL content. These creams are the same in composition but are different with respect to excipient composition, and their texture and physical appearance also vary a bit.

\section{Conclusion}

Stability-indicating method has been developed for the simultaneous determination of HYD and CL in topical creams by reversed-phase high-performance liquid chromatography (RP-HPLC) by a UV detector. The given method is appropriate for HYD and CL assay because the validation of the method confirmed that the method is linear, selective, reproducible, and accurate.

Stability-indicating experiments were done on topical cream preparation under different conditions like temperature, humidity, and sunlight. Good resolution of HYD and CL was attained. Stability study is done in order to give a shelf life of the topical cream as to endorse the usage and storage conditions.

\section{Abbreviations}

API: Active Pharmaceutical Ingredient; CL: Clotrimazole; HPTLC: Highperformance thin layer chromatography; HYD: Hydrocortisone; ICH: International Council for Harmonization; LC-MS/MS: Liquid chromatography mass spectrometry/mass spectrometry; LOD: Limit of detection; LOQ: Limit of quantification; RH: Relative humidity; RPHPLC: Reversed-phase high-performance liquid chromatography; RSD: Relative standard deviation; TLC: Thin layer chromatography; USP: United States Pharmacopeia; UV: Ultraviolet

\section{Acknowledgements}

We are thankful to all those who have supported us during this project.

\section{Authors' contributions}

DNI developed the idea of research and supervised the project and helped in the interpretation of data. AA has performed all the experiments and was responsible for data acquisition. AN contributed to the interpretation of data and wrote the first draft. MI has proofread the draft and helped with

language and grammatical edits. The authors have read and approved the manuscript.

Funding

There is no funding source for this project.

Availability of data and materials

All data and materials are available upon request.

Ethics approval and consent to participate

Not applicable

Consent for publication

Not applicable

\section{Competing interests}

The authors declare that they have no competing interests.

Received: 2 October 2019 Accepted: 21 July 2020

Published online: 05 August 2020

\section{References}

1. Liddell HG, Scott R (2005) A Greek-English Lexicon. Henry Stuart Jones, rev. In.: Oxford: Clarendon Press. Perseus Digital Library Project.

2. Levy LA (1997) Epidemiology of onychomycosis in special-risk populations. J Am Podiatr Med Assoc 87(12):546-550

3. Gräser $Y$, Scott J, Summerbell R (2008) The new species concept in dermatophytes - a polyphasic approach. Mycopathologia 166(5-6):239

4. Metin B, Heitman J (2017) Sexual reproduction in dermatophytes. Mycopathologia 182(1-2):45-55

5. Becker KL (2001) Principles and practice of endocrinology and metabolism: Lippincott Williams \& Wilkins

6. Marcia S, Zini C, Hirsch JA, Chandra RV, Bellini M (2018) Steroids spinal injections. In: Seminars in interventional radiology: 2018: Thieme Medical Publishers; 290-298.

7. Krishnan K (2018) Role of corticosteroids in oral and maxillofacial surgery. J Pharma Sci Res 10(1):208-210

8. Kavakçıŏlu B, Tarhan L (2018) Yeast caspase-dependent apoptosis in Saccharomyces cerevisiae BY4742 induced by antifungal and potential antitumor agent clotrimazole. Arch Microbiol 200(1):97-106

9. Loyd V, Allen J (2018) Anhydrous ointment for diabetic foot ulcer. US Pharm 43(10):59-60

10. Panachiyil GM, Babu T, Sebastian J, Ravi MD (2019) Ampicillin induced oral candidiasis: a case report. Ind J Pharm Prac 12(1):56-58

11. Titcomb LC (2000) Over-the-counter ophthalmic preparations. Pharm J 264:212-218 
12. De Boer H, Lansaat P, Van Oort W (1980) Polarographic analysis for corticosteroids: part 4. Determination of Corticosteroids in Multicomponent and Complex Pharmaceutical Preparations. Anal Chim Acta 116(1):69-76

13. Holak W, Plank WM (1980) Differential pulse polarographic determination of colchicine. J Pharmacol Sci 69(12):1436-1438

14. Döppenschmitt S, Scheidel B, Harrison F, Surmann J (1995) Simultaneous determination of prednisolone, prednisolone acetate and hydrocortisone in human serum by high-performance liquid chromatography. J Chromatogr B Biomed Sci Appl 674(2):237-246

15. Doeppenschmitt S, Scheidel B, Harrison F, Surmann J (1996) Simultaneous determination of triamcinolone acetonide and hydrocortisone in human plasma by high-performance liquid chromatography. J Chromatogr B Biomed Sci Appl 682(1):79-88

16. Gallego JL, Arroyo JP (2002) Spectrophotometric determination of hydrocortisone, nystatin and oxytetracycline in synthetic and pharmaceutical preparations based on various univariate and multivariate methods. Anal Chim Acta 460(1):85-97

17. Pyka A, Babuska-Roczniak M, Bochenska P (2011) Determination of hydrocortisone in pharmaceutical drug by TLC with densitometric detection in UV. J Liq Chromatogr Relat Technol 34(9):753-769

18. Ray JA, Kushnir MM, Rockwood AL, Meikle AW (2011) Analysis of cortisol, cortisone and dexamethasone in human serum using liquid chromatography tandem mass spectrometry and assessment of cortisol: cortisone ratios in patients with impaired kidney function. Clin Chim Acta 412(13-14):1221-1228

19. Kushnir MM, Neilson R, Roberts WL, Rockwood AL (2004) Cortisol and cortisone analysis in serum and plasma by atmospheric pressure photoionization tandem mass spectrometry. Clin Biochem 37(5):357-362

20. Mahmood S, Ahmad Z, Aslam M, Naeem F, Hussain A, Kumar N (2015) Method development and validation for the estimation and evaluation of clotrimazole (an antifungal drug) in tablet preparation by UV-VIS spectroscopy. Int J Pharm Sci Rev Res 32(2):55-58

21. Mousa BA, El-Kousy NM, El-Bagary RI, Mohamed NG (2008) Stability indicating methods for the determination of some anti-fungal agents using densitometric and RP-HPLC methods. Chem Pharm Bull 56(2):143-149

22. Abdel-Moety E, Khattab F, Kelani K, AbouAl-Alamein A (2002) Chromatographic determination of clotrimazole, ketoconazole and fluconazole in pharmaceutical formulations. II Farmaco 57(11):931-938

23. Al-Shidhani A, Al-Rawahi N, Al-Rawahi A, Sathiya Murthi P (2015) Nonsteroidal anti-inflammatory drugs (NSAIDs) use in primary health care centers in A'Seeb, Muscat: a clinical audit. Oman Med J 30(5):366-371

24. Parmar P, Mehta A (2009) Development and validation of HPTLC method for the estimation of clotrimazole in bulk drug and tablet formulation. Ind J Pharma Sci 71(4):451-454

25. Genete G, Hymete A, Ahmed Bekhit A (2012) Development and validation of HPTLC assay method for simultaneous quantification of hydrocortisone and clotrimazole in cream and applying for stability indicating test. J Chin Chem Soc 57(3):1199-1203

26. Nahler $G$ (2009) International Conference on Harmonisation (ICH). In: Dictionary of Pharmaceutical Medicine. edn.: Springer 96-96.

27. Rignall A (2017) ICHQ1A (R2) Stability testing of new drug substance and product and ICHQ1C stability testing of new dosage forms. ICH Quality Guidelines: An Implementation Guide.

28. Bajaj S, Singla D, Sakhuja N (2012) Stability testing of pharmaceutical products. J App Pharm Sci 2(3):129-138

29. Ali A, ATHAR M, Ahmed M, Nadeem K, Murtaza G, Farooq U, Salman M (2019) Stability-indicating HPLC-PDA assay for simultaneous determination of paracetamol, thiamine and pyridoxal phosphate in tablet formulations. Acta Pharma 69(2):249-259

30. Procedures A (2000) Method Validation Chemistry, Guidance for Industry, SIC Manufacturing and Controls Documentation, US Department of Health and Human Services. In.: FDA.

31. Singh S, Bakshi M (2000) Stress test to determine inherent stability of drugs. Pharm Technol 4:1-14

32. Dantus MM, Wells ML (2004) Regulatory issues in chromatographic analysis in the pharmaceutical industry. J Liq Chromatogr Relat Technol 27(7-9):1413-1442

\section{Publisher's Note}

Springer Nature remains neutral with regard to jurisdictional claims in published maps and institutional affiliations.

\section{Submit your manuscript to a SpringerOpen ${ }^{\circ}$ journal and benefit from:}

- Convenient online submission

- Rigorous peer review

- Open access: articles freely available online

High visibility within the field

- Retaining the copyright to your article

Submit your next manuscript at $\boldsymbol{\nabla}$ springeropen.com 